\title{
Pengembangan Variasi Latihan Teknik Blok Bolavoli untuk Siswa Ekstrakurikuler SMA
}

\author{
Muhammad Anwar Syarif*, Roesdiyanto, Prisca Widiawati \\ Universitas Negeri Malang, Jl. Semarang No. 5 Malang, Jawa Timur, Indonesia \\ *Penulis korespondensi, Surel: sariefvinsmoke123@gmail.com
}

Paper received: 31-9-2021; revised: 14-9-2021; accepted: 21-9-2021

\begin{abstract}
The purpose of this study was to develop variations of volleyball block technique exercises for students of SMA Plus Darussalam. The method used is Research and Development (R\&D) using a modified ADDIE step. Based on the results of data analysis from the validation of 3 volleyball coaching experts, a percentage of 83 percent was obtained. From these results it can be concluded that the product developed is feasible to use.
\end{abstract}

Keywords: development; exercise variations; block ball techniques

\begin{abstract}
Abstrak
Tujuan dari penelitian ini adalah untuk mengembangkan variasi latihan teknik blok bolavoli untuk siswa SMA Plus Darussalam. Metode yang digunakan adalah Research and Development (R\&D) dengan menggunakan langkah ADDIE yang telah dimodifikasi. Berdasarkan hasil analisis data dari validasi 3 ahli kepelatihan bolavoli diperoleh persentase sebesar 83 persen. Dari hasil tersebut dapat disimpulkan bahwa produk yang dikembangkan layak digunakan.
\end{abstract}

Kata kunci: pengembangan; variasi latihan; teknik blok bolavoli

\section{Pendahuluan}

Pada tahun 2016 National Alliance for Youth Sports (NAYS) mencatat sebanyak 65\% anak-anak di seluruh dunia terlibat dalam aktivitas olahraga (Felfe, C., Lechner, M., \& Steinmayr, A. 2016). Didasarkan pernyataan tersebut dapat dikatakan kegiatan olahraga sangat digemari anak-anak di seluruh dunia. Kegiatan olahraga dapat dilakukan dimanapun, baik itu di rumah, di klub, di sekolah dan sebagainya. Pada kasus tertentu, banyak dari mereka yang termotivasi melakukan kegiatan olahraga tetapi tidak memperoleh kesempatan untuk berpartisipasi seperti tidak memperoleh dukungan dari orang tua untuk mengikuti klub karena terkendala masalah ekonomi dan sosial (Eime, R. M., Harvey, J. T., Craike, M. J., Symons, C. M., \& Payne, W. R. 2013). Berbeda jika dibandingkan dengan mengikuti olahraga di sekolah atau pada saat kegiatan ekstrakurikuler olahraga yang memberikan akses yang mudah dan tidak membutuhkan biaya serta kurang kompetitifnya persaingan antara sesama jika dibandingkan dengan klub yang terorganisir (Van Acker, R., De Bourdeaudhuij, I., De Martelaer, K., Seghers, J., Kirk, D., Haerens, L, \& Cardon, G. 2011).

Di Indonesia, khususnya yang bersekolah pada tingkat menengah atas atau bisa disebut SMA, kegiatan olahraga biasa dilakukan pada jam pelajaran olahraga maupun pada saat ekstrakurikuler. Ekstrakurikuler sendiri adalah kegiatan yang bertempat di sekolah dan dilakukan di luar jam pelajaran, pada prinsipnya kegiatan ekstrakurikuler harus menyenangkan dan membantu menumbuhkan potensi-potensi yang dimiliki oleh siswa (Permendikbud, No 81A tahun 2013). Selain itu, kegiatan ekstrakurikuler juga dapat meningkatkan kesehatan fisik dan mental siswa (Meyer, U., Romann, M., Zahner, L., Schindler, 
C., Puder, J. J., Kraenzlin, M., ... \& Kriemler, S. 2011). Kegiatan ekstrakurikuler yang disediakan khususnya olahraga di tiap sekolah dapat diasumsikan berbeda-beda seperti futsal, basket bolavoli dan lain-lain tergantung sarana dan prasarana yang dimiliki atau disediakan oleh pihak sekolah.

Permainan bolavoli adalah permainan yang dilakukan oleh 2 tim yang dipisahkan oleh net yang mana setiap tim mempunyai 6 orang. Dalam pelaksanaannya permainan ini bertujuan untuk menempatkan atau mematikan bola melewati net di daerah lawan dan berusaha memenangkan permainan sampai dengan skor 25 poin. Dalam pelaksanaannya, permainan bolavoli memiliki empat teknik dasar yakni servis, passing, smash dan blok. Menurut Patsiaouras, A., Moustakidis, A., Charitonidis, K. and Kokaridas, D., (2011) mengatakan bahwa kualitas permainan bolavoli atau penentu kemenangan kemenangan dalam permainan bolavoli tergantung pada penguasaan teknik dasar.

Dalam permainan bolavoli terdapat satu teknik yang sangat diperhitungkan perannya yaitu teknik blok, sebab teknik ini berperan sebagai pertahanan pertama untuk menangkis serangan lawan yang dilakukan di atas net (Winarno, 2013). Teknik blok dapat dilakukan individu atau dikombinasikan dengan pemain lain dengan membentuk blok 2 atau 3 orang (McKeever, 2018). Untuk melakukan teknik blok dengan baik seorang pemain harus dapat meramalkan atau membaca dengan cepat arah serangan atau pukulan bola yang dilakukan oleh tim lawan. Ketepatan posisi dan timing saat melakukan blok harus diperhitungkan dengan baik (Vute, 2009). Hal ini selaras dengan Silva, Lacerda, \& João, (2014) yang mengatakan bahwa secara variabel yang mempengaruhi keberhasilan dalam melakukan blok adalah timing saat melakukan blok dan dapat menempatkan posisi sesuai arah serangan lawan dengan tepat. Tujuan utama melakukan blok tidak terbatas pada melakukan pertahanan saja tetapi juga untuk memperoleh poin (Lebedew, 2018). Sebab itu, bagi pemain yang berposisi atau ditempatkan sebagai seorang pemblok perlu sekali berlatih teknik blok dengan baik dan benar agar hasil latihan sesuai dengan apa yang diinginkan atau maksimal.

Untuk menguasai teknik blok, diperlukan latihan-latihan yang haruslah menunjang pada teknik blok. Selama proses latihan, dipastikan latihan yang dilakukan bervariasi untuk mengatasi monoton dan kebosanan (Budiwanto, 2012). Sebab pada dasarnya latihan memerlukan waktu yang tidak singkat agar memperoleh adaptasi fisiologis yang bermanfaat, sehingga ancaman kebosanan dan monoton dalam latihan kemungkinan akan terjadi (Hazeldine, 1989). Maka, pelatih dituntut untuk mengetahui banyak jenis latihan yang memungkinkan perubahan secara periodik dalam pelaksanaan latihan (Budiwanto, 2012).

SMA Plus Darussalam merupakan salah sekolah yang menyediakan kegiatan ekstrakurikuler olahraga permainan bolavoli. Berdasarkan hasil observasi awal yang dilakukan peneliti kepada pelatih ekstrakurikuler bolavoli SMA Plus Darussalam dengan memberikan kuesioner analisis kebutuhan. Ditemukan bahwa kurangnya variasi latihan teknik blok bolavoli yang diberikan, sehingga siswanya merasa bosan dengan latihan teknik blok yang monoton, untuk itu pelatih menyatakan membutuhkan pengembangan variasi latihan teknik blok.

Pada penelitian sebelumnya, terdapat penelitian yang berkaitan tentang variasi latihan teknik blok bolavoli yaitu oleh Nuri Hartanto (2018) dalam penelitiannya yang berjudul "Pengembangan Variasi Latihan Block Kombinasi Defense pada bolavoli tahun 2018". Dalam pengembangan ini produk yang dihasilkan berisi 8 variasi. Produk latihan yang 
dikembangkan semuanya ditujukan untuk latihan teknik blok tunggal dan pada pelaksanaannya hanya bisa digunakan oleh satu siswa untuk setiap variasi. Sedangkan produk yang akan dikembangkan dalam penelitian ini berbeda dari penelitian sebelumnya. Produk yang akan dikembangkan ini untuk siswa ekstrakurikuler SMA Plus Darussalam, yang mana produk lebih variatif dengan berisi variasi latihan blok tunggal, ganda dan kelompok yang berjumlah 10 variasi dan dalam pelaksanaannya dapat dilakukan oleh semua siswa atau beberapa siswa sekaligus dalam satu variasi latihan.

Berdasarkan latar belakang yang telah diuraikan di atas, maka peneliti melakukan penelitian yang berjudul "Pengembangan Variasi Latihan Teknik Blok Bolavoli untuk Siswa Ekstrakurikuler SMA Plus Darussalam".

\section{Metode}

Jenis penelitian yang digunakan dalam penelitian ini adalah Research and Development (R\&D) dengan menggunakan langkah ADDIE (Analyze, Design, Development, Implementation and Evaluation) yang dimodifikasi disebabkan pandemi sebagai berikut: (1) analisis kebutuhan (Analyze), (2) Perancangan Produk (Design), Validasi Ahli \& Revisi (Development) sehingga menghasilkan produk variasi latihan teknik blok untuk siswa ekstrakurikuler SMA Plus Darussalam. Proses pengumpulan data yang dilakukan dalam penelitian ini menggunakan kuesioner. Saat proses validasi, produk divalidasi oleh 3 ahli kepelatihan bolavoli yang berprofesi sebagai dosen FIK UM. Teknik analisis data yang digunakan deskriptif kuantitatif yakni persentase. Adapun Kriteria persentase dari hasil yang didapatkan terdapat pada tabel berikut (Arikunto, 2010):

Tabel 1. Kriteria Kelayakan Produk

\begin{tabular}{ccc}
\hline No & Persentase (\%) & Kriteria \\
\hline 1 & $68-100$ & Layak \\
2 & $34-67$ & Cukup Layak \\
3 & $0-33$ & Kurang Layak \\
\hline
\end{tabular}

\section{Hasil dan Pembahasan}

\subsection{Hasil}

Tabel 2. Hasil Analisis Data Ahli Kepelatihan Bolavoli

\begin{tabular}{ccccccc}
\hline No & Indikator & $\begin{array}{c}\text { Ahli } \\
\text { Kepelatihan } \\
\text { Bolavoli 1 }\end{array}$ & $\begin{array}{c}\text { Ahli } \\
\text { Kepelatihan } \\
\text { Bolavoli 2 }\end{array}$ & $\begin{array}{c}\text { Ahli } \\
\text { Kepelatihan } \\
\text { Bolavoli 3 }\end{array}$ & $\begin{array}{c}\text { P } \\
\mathbf{( \% )}\end{array}$ & Kriteria \\
\hline $\mathbf{1}$ & Kemenarikan & 10 & 7 & 8 & $83 \%$ & Layak \\
$\mathbf{2}$ & Kemudahan & 10 & 8 & 8 & $86 \%$ & Layak \\
$\mathbf{3}$ & Ketepatan & 8 & 8 & 8 & $80 \%$ & Layak \\
& Jumlah & $\mathbf{2 8}$ & $\mathbf{2 3}$ & $\mathbf{2 4}$ & $\mathbf{8 3 \%}$ & Layak \\
\hline
\end{tabular}

Berdasarkan hasil validasi 3 ahli kepelatihan bolavoli terhadap produk yang dikembangkan didapatkan jumlah sebesar $83 \%$. Jika dilihat dari kriteria yang terdapat pada tabel 1 di atas, maka produk memperoleh kriteria layak dan dapat digunakan untuk latihan teknik blok bolavoli siswa ekstrakurikuler SMA Plus Darussalam. 


\subsection{Pembahasan}

Pada dasarnya dalam melaksanakan latihan harus bervariasi, sebab variasi adalah salah satu prinsip latihan yang bertujuan untuk mengatasi ancaman terjadinya kebosanan dan monoton dalam pelaksanaan latihan (Budiwanto, 2012). Variasi latihan juga dapat meningkatkan motivasi berolahraga dan membuat suasana latihan jadi menyenangkan (BazValle E, Schoenfeld BJ, Torres-Unda J, Santos-Concejero J, Balsalobre-Fernández C. 2019). Selain itu, variasi latihan dapat meningkatkan ketertarikan, mempermudah proses latihan dan dapat menunjang keterampilan (Budiman, 2016). Irfandi, Sugiyanto, \& A. K. (2015) menyimpulkan bahwa variasi latihan efektif dan efisien digunakan dalam latihan. Produk akhir pengembangan variasi latihan teknik blok bolavoli ini dikemas dalam buku. Produk pengembangan ini berisi 10 variasi latihan teknik blok bolavoli, setiap variasi berisi gambar pelaksanaan, cara pelaksanaan, peralatan dan siswa yang dibutuhkan serta point pelatihan yang berisi kategori, tujuan dan manfaat variasi.

Adapun produk yang telah dikembangkan ini tentunya memiliki kelebihan dan kekurangan dari produk penelitian sebelumnya. Untuk kelebihan yang dimiliki produk pengembangan ini yakni variasi yang dikembangkan lebih variatif dengan berisi 10 variasi latihan teknik blok untuk individu dan berpasangan baik itu 2 atau 3 orang. Jika dibandingkan dengan produk penelitian sebelumnya yang hanya berisi 8 variasi latihan teknik blok dan hanya ditujukan untuk individu saja, hal ini tentu menjadi suatu kelebihan dibandingkan produk sebelumnya, sebab pada dasarnya teknik blok sendiri terbagi menjadi teknik blok individu dan berpasangan baik itu 2 atau 3 orang (McKeever, 2018). Tidak hanya terbatas pada teknik blok individu seperti yang terdapat pada produk penelitian sebelumnya. Sehingga, bisa dikatakan produk pengembangan ini akan membuat peningkatan teknik blok lebih baik daripada produk sebelumnya (Yudasmara, 2010). Untuk kekurangan yang dimiliki produk ini adalah tidak diujicobakan kepada siswa disebabkan situasi pandemi yang tidak memungkinkan pertemuan untuk melakukan uji coba langsung antara peneliti dan siswa.

\section{Simpulan}

Dapat disimpulkan hasil dari penelitian dan pengembangan ini bahwa produk variasi latihan teknik blok bolavoli untuk siswa ekstrakurikuler SMA Plus Darussalam layak digunakan sebab telah memperoleh hasil validasi 3 ahli kepelatihan bolavoli sebesar $83 \%$ dengan kriteria layak. Dengan demikian produk yang telah dikembangkan dapat mengatasi permasalahan yang dialami oleh pelatih ekstrakurikuler SMA Plus Darussalam pada saat kegiatan ekstrakurikuler berlangsung dan diharapkan dapat memudahkan siswa untuk menguasai teknik blok. Selain itu, diharapkan dengan adanya penelitian ini dapat dijadikan referensi untuk penelitian-penelitian berikutnya mengenai variasi latihan teknik blok seperti di klub dan sejenisnya.

\section{Daftar Rujukan}

Arikunto, S. (2010). Prosedur peneltian Suatu Pendekatan Praktik. Jakarta: Rineka Cipta

Baz-Valle, E., Schoenfeld, B. J., Torres-Unda, J., Santos-Concejero, J., \& Balsalobre-Fernández, C. (2019). The effects of exercise variation in muscle thickness, maximal strength and motivation in resistance trained men. Plos one, 14(12), e0226989.

Budiman, I. A. (2016). Development model of volleyball spike training. International Journal of Physical Education, Sports and Health, 3(3), 466-471.

Budiwanto, (2012). Metodologi Penelitian Olahraga. Malang: Fakultas Ilmu Keolahragaan. Universitas Negeri Malang. 
Eime, R. M., Harvey, J. T., Craike, M. J., Symons, C. M., \& Payne, W. R. (2013). Family Support and Ease of Access Link Socio-Economic Status and Sports Club Membership in Adolescent Girls: A Mediation Study. International Journal of Behavioral Nutrition and Physical Activity, 10(1), 50. doi:10.1186/1479-586810-50.

Felfe, C., Lechner, M., \& Steinmayr, A. (2016). Sports and child development. PloS one, 11(5), e0151729.

Forman., J., Lebedew., M., (2018) Volleyball Coaching Wizart. USA

Hartato, N. (2018). Pengembangan Variasi Latihan Block Kombinasi Defence Pada Bola Voli Tahun 2018. Fakultas Ilmu Keolahragaan, Universitas Negeri Medan, Medan, Indonesia.

Hazeldine, R., (1985). Fitness for Sport, Malborough: The Crowood Press.

Kristiyanto, A. (2015). Pengembangan Model Latihan Teknik Servis Bawah, Servis Atas dan Cekis dalam Bolavoli. Jurnal Penjaskesrek, 2(2), 22-50.

McKeever. (2018). Volleyball. England: English Volleyball Association with Royal Navy.

Meyer, U., Romann, M., Zahner, L., Schindler, C., Puder, J. J., Kraenzlin, M., ... \& Kriemler, S. (2011). Effect of a general school-based physical activity intervention on bone mineral content and density: a clusterrandomized controlled trial. Bone, 48(4), 792-797.

Patsiaouras, A., Moustakidis, A., Charitonidis, K. \& Kokaridas, D., (2011). Technical Skills That Lead in Winning or Losing Volleyball Matches During The Beijing Olympics. Journal of Physical Education and Sports, 11 (2), p. 149.

Silva, M., Lacerda, D. \& João, P. V. (2014). Match analysis of discrimination skills according to the setter defence zone position in high level volleyball. International Journal of Performance Analysis in Sport, 14(2), 463472.

Van Acker, R., De Bourdeaudhuij, I., De Martelaer, K., Seghers, J., Kirk, D., Haerens, L, \& Cardon, G. (2011). A Framework for Physical Activity Programs within School-community Partnerships. Quest, 63(3), 300320.

Vute, R. (2009). Teaching and Coaching Volleyball For Disable. Faculty of Education, University of Ljubljana, Ljubljana.

Winarno. (2013). Teknik Dasar Bermain Bolavoli. Fakultas Ilmu Keolahragaan, Universitas Negeri Malang. Malang, Indonesia. 